\title{
Investigational agents in metastatic basal cell carcinoma: focus on vismodegib
}

This article was published in the following Dove Press journal:

Journal of Experimental Pharmacology

30 August 2012

Number of times this article has been viewed

\author{
Nicolas Batty' \\ Ellen Kossoff ${ }^{2}$ \\ Grace K Dy' \\ 'Department of Medicine, Roswell \\ Park Cancer Center, Buffalo, NY, USA; \\ ${ }^{2}$ Department of Pharmacy, Roswell \\ Park Cancer Center, Buffalo, NY, USA
}

\begin{abstract}
Vismodegib (GDC-0449, 2-chloro-N-(4-chloro-3-(pyridin-2-yl)phenyl)-4(methylsulfonyl)benzamide, Erivedge ${ }^{\mathrm{TM}}$ ) is a novel first-in-human, first-in class, orally bioavailable Hedgehog pathway signaling inhibitor of the G-protein coupled receptor-like protein smoothened (SMO) which was approved in the United States on January 2012. This signaling pathway is involved in the carcinogenesis of several types of tumor, as exemplified by basal cell carcinoma. This review focuses on the role of the Hedgehog pathway in the pathogenesis of basal cell carcinoma, the pharmacology and the clinical activity of vismodegib, as well as a brief summary of investigational agents in development targeting this pathway.

Keywords: hedgehog inhibitors, metastatic basal cell carcinoma, hedgehog signalling pathway
\end{abstract}

\section{Background}

Basal cell carcinoma (BCC) is the most common human malignancy. ${ }^{1}$ Fortunately, BCC rarely becomes metastatic. Most of the 1 million cases per year in the United States are localized and treated with surgical excision. ${ }^{2}$ The risk of developing metastatic disease ranges from 0.0028 to 0.55 percent. ${ }^{1}$ The time from initial tumor to metastases is about 9 years, the survival of which ranges from 8 months to 3.6 years. ${ }^{1}$ Sites of metastatic disease include the regional lymph nodes, bone, lung, and liver. Several factors increase the risk of subclinical extension and subsequent recurrent and/or metastatic disease: initial tumor size over two centimeters, lesions originating on the central part of the face or ears, long duration of original lesion, incomplete excision, an aggressive histological growth pattern, or involvement of the perineural or perivascular areas. ${ }^{1}$ Tumors with indistinct borders and extension from the original lesion are more often associated with positive margins after excision. These tumors also have a higher recurrence rate compared to well-defined and limited tumors. ${ }^{3}$ The low prevalence of advanced disease is due to several reasons such as the indolent nature of the disease, the early detection of small, visible lesions on the skin, and the high cure rate of surgical resection. ${ }^{3}$ However, in rare instances, this disease is incurable when the tumors become unresectable and metastasize. The new class of targeted agents, Hedgehog (Hh) antagonists, which inhibit the driving force of BCC pathogenesis, offers optimism in an arena where no other proven standard treatment is available.

\section{The role of the hedgehog pathway}

In 1980, while they were examining mutations that may disrupt the growth of the fruit fly Drosophila, Christiane Nusslein-Volhard and Eric F. Weischaus discovered 
the Hedgehog gene. ${ }^{4}$ This gene was named after the "spiked" phenotype of the cuticle of the Hedgehog mutant larvae of Drosophila. ${ }^{5}$ The Hedgehog family of proteins was shown later to play a vital role in vertebrate embryonic development. There are three Hh homologs that act as ligands: Sonic Hedgehog $(\mathrm{SHH})$, Indian Hedgehog $(\mathrm{IHH})$ and Desert Hedgehog (DHH). ${ }^{6}$ Cell fate control, patterning, proliferation, survival and differentiation were implicated in varying contexts with Hh members. These are essential in the development of the embryonic tissue that controls the movement and organization of cells throughout morphogenesis. This process occurs by forming a concentration gradient or by acting as mitogens. The latter are involved in the regulation of cell proliferation and shaping developing organs. ${ }^{6}$ The Hh signaling pathway can be dysregulated by either ligand-dependent or ligand- independent mechanisms for which there are at least three basic models proposed to underscore the molecular events involved. ${ }^{7}$ The type I model refers to ligand-independent constitutive activation of $\mathrm{Hh}$ pathway arising from mutations that either inactivate the negative regulators (eg, mutations in PTCH1 or SUFU) or activate the receptor smoothened homolog (mutations in $S M O$ ) and/or its downstream mediators such as via amplification of the GLI1 transcription factor (Figure 1). Type II model refers to ligand-dependent pathway activation via autocrine loop signals, such as secretion of Hh ligands that binds to PTCH1 on cancer cells. Liganddependent paracrine signaling classically refers to the Type III model wherein there is activation of stromal cells by $\mathrm{Hh}$ ligands secreted by tumor cells, which in turn receives other growth signals from the stroma. A newer variation, called

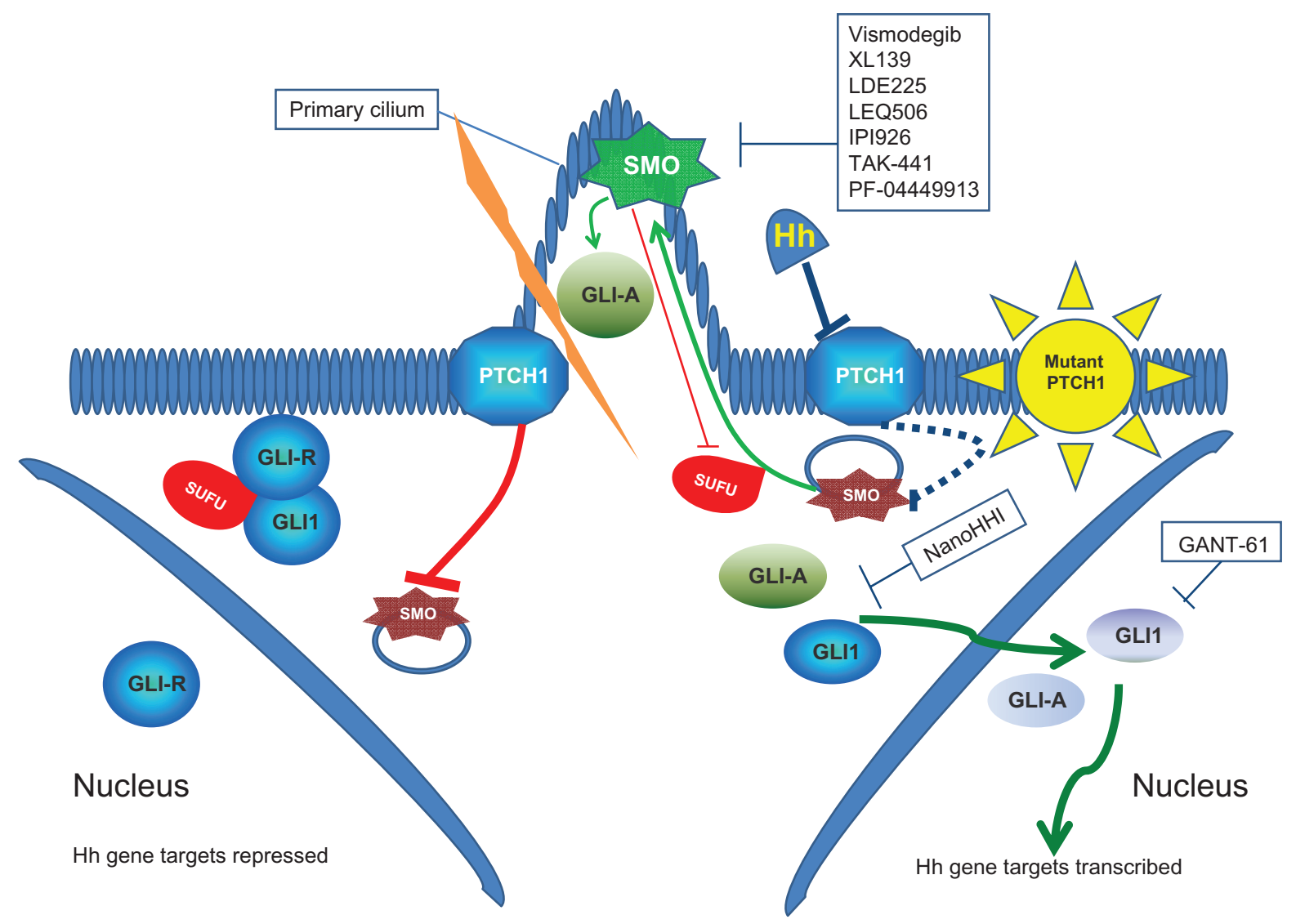

Figure I Hedgehog $(\mathrm{Hh})$ signaling.

Notes: Normal activation of the signaling pathway results from the binding of Hh ligand to the I2-transmembrane patched I (PTCHI). As represented in the left half of the figure (demarcated by the jagged orange line), the absence of the Hh ligand allows PTCHI to repress the activity of the seven-transmembrane G protein coupled receptorlike receptor smoothened homolog (SMO) which is located in intracellular endosomes. Under this state, the GLI transcription factors GLI2 and GLI3 form a complex with the regulatory suppressor of fused (SUFU) protein, which is then either degraded by the proteasome or processed into repressor forms that cannot activate target gene transcription. ${ }^{42}$ SUFU also acts to sequester GLII, which is constitutively active and does not contain repressor domain. ${ }^{43}$ When Hh ligand is available as represented in the right half of the figure, PTCHI exits out of the primary cilium and permits SMO to translocate to the plasma membrane, concentrating in the cilia of some cell types. Activated SMO suppresses SUFU function, which renders the GLIs stable and active, such as by reduction of repressor forms. In the nucleus, activated GLI permits the target gene expression, such as CCNDI, PTCHI, and GLII. Type I Hh signaling is ligand-independent aberrant activation, such as by functional inactivation of PTCHI through mutations resulting in constitutive activation of SMO and downstream GLI-mediated transcription of genes. Drugs inhibiting SMO are shown in the text boxes.

Abbreviations: GLI-R, GLI2 and GLI3 repressor forms; GLI-A, GLI2 and GLI3 transcriptional activators; Hh, Hedgehog; NanoHHI, polymeric nanoparticle formulation of Hh pathway inhibitor-I; PTCHI, patched I; SMO, smoothened; SUFU, suppressor of fused. 
type IIIb, is a reverse paracrine signaling whereby Hh ligands secreted by cells in the stroma leads to Hh pathway activation in the cancer cell (reviewed in detail by Scales et $\mathrm{al}^{8}$ ). Moreover, evidence is emerging supporting the role of $\mathrm{Hh}$ pathway in mediating treatment resistance and disease relapse through the maintenance of putative cancer stem cells in the microenvironment. ${ }^{7}$

The type I aberrant Hh signaling has been identified as the key molecular event implicated in BCC tumorigenesis. ${ }^{5,6}$ The tumorigenic potential of deregulated Hh signaling was first identified in BCC. Family-based linkage studies of patients with Gorlin's syndrome have led to the discovery of the causative mutation. It was mapped to the Patched 1 gene (PTCH1) on chromosome 9. ${ }^{9}$ Loss of PTCH1 predisposes patients with Gorlin's syndrome to develop BCC. In 90\% of sporadic form of BCC, at least one allele of PTCH1 is the identifiable mutation and the remainder of $10 \%$ has activating mutations in the SMO (gain of function) that reduces inhibition by PTCH1. Unrestrained constitutive signaling of the $\mathrm{Hh}$ pathway causes proliferation of basal cells in mouse models of BCC. ${ }^{10}$ As type I mechanism is ligand-independent, inhibition of the ligand-PTCH1 interface, such as the use of monoclonal antibodies or trap agents will not be effective.

\section{Overview of current therapeutic strategies}

The therapeutic modalities for patients with advanced/inoperable BCC are limited. Traditionally, systemic chemotherapy has been utilized in this setting and allogeneic organ transplantation in specific cases. The level of supporting evidence is weak as it is based on case reports; the lack of randomized controlled clinical trials is due to the low prevalence of metastatic BCC. A review of the literature revealed that cisplatinbased regimens are relatively effective in treating this disease. This is based on several case reports. ${ }^{11,12}$ Nonetheless, the NCCN guideline continues not to recommend a specific chemotherapy regimen in this setting.

\section{Vismodegib}

Vismodegib is a small molecule inhibitor of the receptor SMO. ${ }^{13,14}$ It was approved by the United States Food and Drug Administration (FDA) on January 30, 2012 for the treatment of adults with metastatic basal cell carcinoma or with locally advanced basal cell carcinoma which recurred following surgery or who are not candidates for surgery/radiation based on efficacy results in 104 patients demonstrated in a single-arm parallel cohort trial. ${ }^{15}$ In this nonrandomized trial examining 33 patients with metastatic BCC and 71 cases ineligible for surgery and/or radiation therapy, the median duration of response was 7.6 months and the overall response rates by independent review were $30 \%$ and $43 \%$ in patients with metastatic and locally advanced $\mathrm{BCC}$, respectively. Patients were shown to be able to remain on the treatment for approximately a year with acceptable toxicities. ${ }^{15}$

\section{Pharmacokinetics/pharmacodynamics}

Following a single oral fasting dose of vismodegib in a phase I study in cancer patients, the maximum total or unbound plasma concentrations were achieved by the second day, with sustained plasma level concentration observed throughout the 6-day washout period. ${ }^{16}$ Interestingly, with multiple dosing, steady-state concentrations (Css) were achieved earlier than expected (estimated half-life is approximately 10-14 days following a single 150 -mg oral dose in healthy volunteers), ${ }^{17}$ ie, within 7-14 days. ${ }^{16}$ Unbound drug constituted less than $1 \%$ of total drug concentrations regardless of dose or total plasma concentration. ${ }^{16}$ Moreover, with multiple daily dosing, there was lack of dose-proportionality in the Css, ie, average Css was similar across different dose cohorts (150 mg, $270 \mathrm{mg}, 540 \mathrm{mg}$ ), suggesting nonlinear pharmacokinetics. ${ }^{16}$ Pharmacodynamic evaluation of post-treatment normal skin biopsy showed downregulation of GLI1 mRNA expression in approximately $75 \%$ of patients compared with pretreatment specimens, without correlation between the magnitude of GLII downregulation and dose cohort. ${ }^{14}$ The recommended phase II dose was thus established at the lowest dose cohort of $150 \mathrm{mg} /$ day since higher doses did not result in increased steady state plasma drug concentration and no dose-limiting toxicities were observed. ${ }^{14}$

PK modeling suggested that saturable, solubility-limited absorption could explain the nonlinearity in terms of dose, and slow clearance for the sustained concentrations, whereas high protein-binding component can explain the small volume of distribution and the low, unbound fraction. ${ }^{16}$ Indeed, vismodegib levels were strongly correlated with alpha 1-acid glycoprotein (AAG) levels which it binds with high affinity $(\mathrm{Kd}=13 \mathrm{uM}) .{ }^{18}$ Nonetheless, due to the relative abundant concentration compared to AAG, human serum albumin represents a high-capacity drug-binding protein albeit of lower affinity relative to AAG $(\mathrm{Kd}=120 \mathrm{uM}){ }^{18}$

Due to the nonlinearity as described above, a PK-dose scheduling study was conducted to evaluate whether less frequent dosing can result in similar steady-state levels achieved through daily drug administration. ${ }^{19}$ This study randomized patients to either daily dosing, three-times-a-week (TIW) or once weekly (QW) schedule after an initial loading 
phase of daily $150 \mathrm{mg}$ for 11 days. Patients were stratified according to baseline AAG concentration. By day 29 (after two weeks of alternative dosing schedule), total Css was reduced in a less than dose-proportional fashion, with the lowest level in the once-weekly group. Moreover, the reduction in unbound concentration was even more pronounced than the total drug concentrations at a doseproportional fashion suggesting linear PK of unbound vismodegib. By the 6th week of the alternative dosing schedules, the total and unbound vismodegib Css had declined by an average of $24 \%$ and $46 \%$ for the TIW group, and by $50 \%$ and $80 \%$ for the QW group respectively, relative to the initial levels after the loading phase. Only the standard daily dosing regimen provided unbound vismodegib Css in excess of the target $\mathrm{IC}_{95}$ value range of 42 to $68 \mathrm{nmol} / \mathrm{L}$ for GLI1 inhibition. ${ }^{20}$ Whereas the mean unbound Css in the TIW group was greater than the target $\mathrm{IC}_{95}$ values, almost half of the patients in this group had concentrations below the more conservative target level of $68 \mathrm{nmol} / \mathrm{L}$. For the QW group, majority of patients had unbound CSS below the $\mathrm{IC}_{95}$ target. The aforementioned PK modeling developed during the previous phase I studies in fact prospectively predicted the actual PK results eventually observed from this current study. This mechanistic PK model was then extended to explore the effect of using a lower once daily dose on the total and unbound Css, which verified that the optimal dosing is indeed $150 \mathrm{mg}$ once daily. ${ }^{19}$
Healthy volunteer studies of vismodegib showed that nearly all of the total circulating drug-related components are the parent drug (>98\%). ${ }^{21}$ The metabolic pathways of vismodegib in humans include oxidation, glucuronidation, and pyridine ring cleavage. It is eliminated by a combination of slow elimination, extensive metabolism and excretion of parent drug, the majority of which is excreted through the fecal route. Only a minor amount of an administered dose is recovered in urine. ${ }^{21}$

\section{Safety and tolerability}

Due to the known embryotoxic potential of the pathway, stringent pregnancy precautions were used during clinical trials. Vismodegib may not be a therapeutic option for younger patients either as it may interfere with developing teeth and bones. ${ }^{22}$ The most common toxicities observed in the conducted trials to date were primarily constitutional symptoms such as fatigue, gastrointestinal, and musculoskeletal manifestations. Overall, most reported adverse events were of mild to moderate (Common Toxicity Criteria grades 1 and 2) severity, ${ }^{13,14}$ of which muscle spasms and dysgeusia were the most common. Other low-grade toxicities including nausea and vomiting, dyspepsia, alopecia and weight loss were observed. On the other hand, a few grade 3 and 4 toxicities were seen, consisting of weight loss and fatigue in less than $10 \%$ of the examined cases. ${ }^{13,14}$ Fatigue, hyponatremia, muscle spasms, abdominal pain and atrial fibrillation were other rare Grade 3 adverse events. ${ }^{13,14}$ Some of these side effects are not unexpected due to the

Table I Other Hh pathway antagonists ${ }^{41}$

\begin{tabular}{|c|c|c|c|c|c|}
\hline Agent & Solid tumors ${ }^{a}$ & $\begin{array}{l}\text { Hematologic } \\
\text { malignancies }^{\mathrm{b}}\end{array}$ & Phase $^{c}$ & FDA $^{d}$ & Company ${ }^{e}$ \\
\hline XLI39 (BMS 833923) & $\begin{array}{l}\text { Inoperable, metastatic gastric, } \\
\text { gastroesophageal, or esophageal } \\
\text { adenocarcinomas, } \\
\text { Advanced solid tumors, } \\
\text { non-small cell lung cancer }\end{array}$ & $\begin{array}{l}\text { Chronic phase CML } \\
\text { Multiple myeloma }\end{array}$ & $I / I I$ & No & Bristol Myer Squibb \\
\hline LDE225 & $\begin{array}{l}\text { Skin BCC in Gorlin syndrome, } \\
\text { Locally advanced or metastatic } \\
\text { pancreatic cancer }\end{array}$ & Resistant CML & 1 & No & Novartis \\
\hline LEQ506 & Advanced solid tumors & None & I & No & Novartis \\
\hline IPI926 & $\begin{array}{l}\text { Advanced pancreatic } \\
\text { adenocarcinoma, recurrent head } \\
\text { and neck cancer, metastatic or } \\
\text { locally advanced chondrosarcoma }\end{array}$ & Myelofibrosis & Pilot/I/II & No & Infinity \\
\hline TAK-44I & Advanced BCC & None & I & No & Millennium \\
\hline PF-5274857 & Medulloblastoma & & Preclinical & No & Pfizer \\
\hline PF-04449913 & Advanced/metastatic solid tumor & $\begin{array}{l}\text { Refractory hematologic } \\
\text { malignancies, AML, } \\
\text { high risk } \mathrm{MDS}^{6}\end{array}$ & I & No & Pfizer \\
\hline
\end{tabular}

Notes: ${ }^{a}$ Type of solid tumors currently tested; bype of hematological malignancies currently tested; 'type of active clinical trials; ${ }^{\mathrm{d} F D A}$ : approval; ${ }^{\mathrm{e}} \mathrm{pharmaceutical}$ company. Abbreviations: CML, chronic myeloid leukemia; AML, acute myelogenous leukemia; MDS, myelodysplastic syndrome. 
Table 2 Clinical trials of vismodegib, as a single agent or in combination with chemotherapies and/or targeted therapies ${ }^{4}$

\begin{tabular}{|c|c|c|c|c|}
\hline NCT & Regimen & Target population & Status & Phase \\
\hline NCT0I537I07 & Sirolimus and Vismodegib & $\begin{array}{l}\text { Inoperable solid tumors or pancreatic } \\
\text { cancer }\end{array}$ & Recruiting & 1 \\
\hline NCT0I54358I & Vismodegib & $\mathrm{BCC}$ & Not recruiting yet & II \\
\hline NCT0I 367665 & Vismodegib & Locally advanced or metastatic BCC & Recruiting & II \\
\hline NCT0I330I73 & Vismodegib & $\begin{array}{l}\text { High-risk first remission or relapsed } \\
\text { multiple myeloma who received an } \\
\text { autologous stem cell transplant }\end{array}$ & Recruiting & I \\
\hline NCT0I5465I9 & Vismodegib & $\begin{array}{l}\text { Advanced solid malignancies including } \\
\text { hepatocellular carcinoma }\end{array}$ & Not recruiting yet & 1 \\
\hline NCT00878I63 & $\begin{array}{l}\text { Erlotinib and vismodegib } \\
\text { with or without gemcitabine }\end{array}$ & $\begin{array}{l}\text { Metastatic pancreatic cancer or inoperable } \\
\text { solid tumors }\end{array}$ & Unknown & 1 \\
\hline NCT00982592 & $\begin{array}{l}\text { Fluorouracil, leucovorin calcium, } \\
\text { oxaliplatin (FOLFOX) and with } \\
\text { either vismodegib or placebo }\end{array}$ & $\begin{array}{l}\text { Advanced stomach cancer or } \\
\text { gastroesophageal junction cancer }\end{array}$ & Recruiting & II (randomized) \\
\hline NCTOI 267955 & Vismodegib & Advanced chondrosarcomas & Recruiting & II \\
\hline NCT0I064622 & $\begin{array}{l}\text { Gemcitabine with or without } \\
\text { vismodegib }\end{array}$ & Recurrent or metastatic pancreatic cancer & Recruiting & II (randomized) \\
\hline NCT0II 63084 & $\begin{array}{l}\text { Leuprolide acetate or goserelin } \\
\text { with or without vismodegib } \\
\text { followed by surgery }\end{array}$ & Locally advanced prostate cancer & Active, not recruiting & I/II (randomized) \\
\hline NCT00887I59 & $\begin{array}{l}\text { Cisplatin and etoposide with } \\
\text { or without either vismodegib } \\
\text { or cixutumumab }\end{array}$ & Extensive-stage small cell lung cancer & Recruiting & II (randomized) \\
\hline NCTOII54452 & $\begin{array}{l}\text { RO4929097 with or without } \\
\text { vismodegib }\end{array}$ & Advanced or metastatic sarcoma & Recruiting & Ib/II (randomized) \\
\hline NCTOI 239316 & Vismodegib & $\begin{array}{l}\text { Pediatric patients with recurrent } \\
\text { or refractory medulloblastoma }\end{array}$ & Recruiting & II \\
\hline NCT0I0888I5 & Vismodegib & $\begin{array}{l}\text { Metastatic adenocarcinoma of the } \\
\text { pancreas }\end{array}$ & Recruiting & II \\
\hline NCTOI096732 & Vismodegib & $\begin{array}{l}\text { Pancreatic ductal adenocarcinoma } \\
\text { in the preoperative setting }\end{array}$ & Recruiting & II \\
\hline NCT00939484 & Vismodegib & $\begin{array}{l}\text { Adult patients with recurrent or } \\
\text { refractory medulloblastoma }\end{array}$ & Recruiting & II \\
\hline NCTOII954I5 & Gemcitabine and vismodegib & Advanced pancreas cancer & Recruiting & Pilot \\
\hline NCTOI20I9I5 & Vismodegib & Operable BCC & Recruiting & II \\
\hline NCT0I2393I6 & Vismodegib & Recurrent or refractory medulloblastoma & Recruiting & $\|$ \\
\hline NCT0I556009 & $\begin{array}{l}\text { Vismodegib versus photodynamic } \\
\text { therapy }\end{array}$ & Multiple BCCs (eg, Gorlin syndrome) & Not recruiting yet & II (randomized) \\
\hline
\end{tabular}

on-target effects of Hh pathway in taste bud papillae formation and hair follicle growth..$^{23,24}$

\section{Mechanisms of resistance to vismodegib}

In the seminal clinical trial of vismodegib, there was dramatic tumor shrinkage in a patient with metastatic medulloblastoma. ${ }^{14,25}$ Molecular profiling showed that the patient's primary and metastatic tumors prior to vismodegib therapy harbored an inactivating somatic PTCH1 mutation, thus resulting in lack of SMO repression. ${ }^{26}$ Upon disease progression, molecular profiling and re-biopsy of a progressing lesion were performed by the Genentech team led by De Sauvage. ${ }^{26}$ Aside from the previously detected PTCH1 mutation, a new G-to-C missense mutation at position 1697 of SMO was identified, which changed the amino acid from Asp to His in codon 473. ${ }^{26}$ In functional studies performed, SMO-D473H per se does not have oncogenic properties in the presence of wildtype $P$ TCH1. This acquired resistance mutation resulted in a loss of physical interaction between vismodegib and SMO, thereby impairing drug binding to its target. ${ }^{26}$ In fact, substitution of D473 with every other amino acid conferred functional resistance to vismodegib, some of which have oncogenic potential. ${ }^{27}$ Another prospective site of mutation identified using an alanine scan mutagenesis approach was at E518, which conferred resistance to vismodegib while remaining functionally intact. ${ }^{27}$ To overcome these structural limitations, second-generation SMO antagonists, such as 
the bis-amide analogs with activity against vismodegibresistant SMO are in development. ${ }^{28}$

Establishment of drug-resistant tumor cell lines further revealed that other mechanisms of resistance to SMO inhibition maybe mediated downstream of SMO, such as by cyclin D1 (CCND1) or GLI amplification. ${ }^{27,29}$ Moreover, treatment with a PI3K inhibitor greatly reduced tumor growth in both vismodegib-sensitive and -resistant models, ${ }^{27}$ suggesting that tumors with acquired resistance remain dependent on PI3K signaling. Indeed, combination of a SMO inhibitor with a PI3K inhibitor may delay the onset of drug resistance in preclinical models. ${ }^{29}$

\section{Other investigational agents}

Multiple other SMO antagonists are under investigation in the clinic. Overall they are orally administered and are being evaluated in variety of malignancies (Table 1). Several of the adverse events associated with vismodegib are also seen with other Hh antagonists in clinical development (muscle spasms, dysgeusia, alopecia). ${ }^{30-33}$ These events are likely on-target effects as elucidated earlier. Topical administration of LDE225 has shown promising results in a small study among patients with nodular and superficial BCC with tumor response correlating with a decrease in Hh target gene expression. ${ }^{34}$ More recently, calcitriol has been shown to inhibit Hh signaling and proliferation in BCC independent of its effects on the vitamin D receptor. Its target is likely SMO as SMO-deficient cells were unaffected by calcitriol treatment. However, the exact mechanism of activity is yet unknown. ${ }^{35}$

Distinct from SMO antagonists that can overcome resistance to vismodegib mediated by SMO mutations are compounds that target GLI. There are multiple steps in GLI regulation that can be pharmacologically modified. ${ }^{36}$ GANT61 is a small molecule that inhibits GLI1-mediated transcription by interfering with DNA binding. ${ }^{37} \mathrm{NanoHHI}$ is a polymeric nanoparticle formulation of HPI-1, a GLI1 antagonist that disrupts GLI activation and increases GLI repressor forms. ${ }^{36,38} \mathrm{NanoHHI}$ can inhibit Hh signaling in cells with ectopic expression of the SMO D473H mutation. ${ }^{38}$ Naturally occurring inhibitors of GLI-mediated transcription identified from cell-based assay screening include zerumbone, staurosporinone, arcyriaflavin and physalins. ${ }^{39}$

\section{Conclusions and future directions}

Vismodegib is a novel first-in-human, first-in class, orally bioavailable Hedgehog pathway signaling inhibitor of SMO, which was approved in the United States. Numerous clinical trials are recruiting patients to explore the role of vismodegib as monotherapy or in combination with chemotherapies and/or targeted therapies, not only in BCC but in other malignancies as well (Table 2). Successful clinical development of second-generation agents as well as combinatorial approaches with other targeted therapies may help to circumvent the emerging mechanisms of resistance in this setting. Furthermore, research is ongoing to elucidate biomarkers of treatment response and resistance. Enhanced understanding of the function of the primary cilium, a subcellular organelle protruding from the plasma membrane, has revealed its dynamic role in facilitating the transport and interactions of Hh pathway proteins. It has thus been recently suggested that absence of primary cilia in cancer cells may predict lack of efficacy of SMO inhibitors and may explain the lack of response to vismodegib in BCC with PTCH1 or SMO mutations. ${ }^{40}$ This warrants further investigation in prospective studies. Availability of pre- and post-treatment biopsies will facilitate these biomarker and mechanistic studies, which should evaluate both the cancer cell and surrounding stroma as well.

\section{Disclosure}

The authors report no conflicts of interest in this work.

\section{References}

1. Rubin AI, Chen EH, Ratner D. Basal-cell carcinoma. $N$ Engl J Med. 2005;353(21):2262-2269.

2. Stern RS. Prevalence of a history of skin cancer in 2007: results of an incidence-based model. Arch Dermatol. 2010;146(3):279-282.

3. Walling HW, Fosko SW, Geraminejad PA, Whitaker DC, Arpey CJ. Aggressive basal cell carcinoma: presentation, pathogenesis, and management. Cancer Metastasis Rev. 2004;23(3-4):389-402.

4. Nusslein-Volhard C, Wieschaus E. Mutations affecting segment number and polarity in Drosophila. Nature. 1980;287(5785):795-801.

5. Gupta S, Takebe N, Lorusso P. Targeting the Hedgehog pathway in cancer. Ther Adv Med Oncol. 2010;2(4):237-250.

6. Ingham PW, McMahon AP. Hedgehog signaling in animal development: paradigms and principles. Genes Dev. 2001;15(23):3059-3087.

7. Rubin LL, de Sauvage FJ. Targeting the Hedgehog pathway in cancer. Nat Rev Drug Discov. 2006;5:1026-1033.

8. Scales SJ, de Sauvage FJ. Mechanisms of Hedgehog pathway activation in cancer and implications for therapy. Trends in Pharmacol Sci. 2009;30:303-312.

9. Gailani MR, Ståhle-Bäckdahl M, Leffell DJ, et al. The role of the human homologue of Drosophila patched in sporadic basal cell carcinomas. Nat Genet. 1996;14(1):78-81.

10. Grachtchouk M, Mo R, Yu S, et al. Basal cell carcinomas in mice overexpressing Gli2 in skin. Nat Genet. 2000;24(3):216-217.

11. Carneiro BA, Watkin WG, Mehta UK, Brockstein BE. Metastatic basal cell carcinoma: complete response to chemotherapy and associated pure red cell aplasia. Cancer Invest. 2006;24(4):396-400.

12. Denic S. Preoperative treatment of advanced skin carcinoma with cisplatin and bleomycin. Am J Clin Oncol. 1999;22(1):32-34.

13. Von Hoff DD, LoRusso PM, Rudin CM, et al. Inhibition of the hedgehog pathway in advanced basal-cell carcinoma. $N$ Engl J Med. 2009;361(12):1164-1172. 
14. LoRusso PM, Rudin CM, Reddy JC, et al. Phase I trial of hedgehog pathway inhibitor vismodegib (GDC-0449) in patients with refractory, locally advanced or metastatic solid tumors. Clin Cancer Res. 2011;17(8):2502-2511.

15. United States Food and Drug Administration US FDA approval. Vismodegib FDA-approved label. Available from: http://www.accessdata.fda. gov/drugsatfda_docs/label/2012/203388lbl.pdf?et_cid=28678045\&et_r id=463634184\&linkid=http $\% 3 a \% 2 f \% 2 f$. http://www.accessdata.fda. gov $\% 2$ fdrugsatfda_docs $\% 2$ flabel $\% 2$ f2012\%2f203388lbl.pdf. Accessed May 1, 2012.

16. Graham RA, Lum BL, Cheeti S, et al. Pharmacokinetics of hedgehog pathway inhibitor vismodegib (GDC-0449) in patients with locally advanced or metastatic solid tumors: the role of alpha-1-acid glycoprotein binding. Clin Cancer Res. 2011;17(8):2512-2520.

17. Ding X, Chou B, Graham RA, et al. Determination of GDC-0449, a small-molecule inhibitor of the Hedgehog signaling pathway, in human plasma by solid phase extraction-liquid chromatographic-tandem mass spectrometry. J Chromatogr B Analyt Technol Biomed Life Sci. 2010;878(9-10):785-790.

18. Giannetti AM, Wong H, Dijkgraaf GJ, et al. Identification, characterization, and implications of species-dependent plasma protein binding for the oral Hedgehog pathway inhibitor vismodegib (GDC-0449). J Med Chem. 2011;54(8):2592-2601.

19. Lorusso PM, Jimeno A, Dy G, et al. Pharmacokinetic dose-scheduling study of hedgehog pathway inhibitor vismodegib (GDC-0449) in patients with locally advanced or metastatic solid tumors. Clin Cancer Res. 2011;17(17):5774-5782.

20. Wong H, Alicke B, West KA, et al. Pharmacokinetic-pharmacodynamic analysis of vismodegib in preclinical models of mutational and ligand-dependent Hedgehog pathway activation. Clin Cancer Res. 2011;17(14):4682-4692.

21. Graham RA, Lum BL, Morrison G, et al. A single dose mass balance study of the Hedgehog pathway inhibitor vismodegib (GDC-0449) in humans using accelerator mass spectrometry. Drug Metab Dispos. 2011;39(8):1460-1467.

22. Kimura H, Ng JM, Curran T. Transient inhibition of the Hedgehog pathway in young mice causes permanent defects in bone structure. Cancer Cell. 2008;13(3):249-260.

23. St-Jacques B, Dassule HR, Karavanova I, et al. Sonic hedgehog signaling is essential for hair development. Curr Biol. 1998;8(19): 1058-1068.

24. Hall JMH, Bell ML, Finger TE. Disruption of sonic hedgehog signaling alters growth and patterning of lingual taste papillae. Dev Biol. 2003;255(2):263-277.

25. Rudin CM, Hann CL, Laterra J, et al. Treatment of medulloblastoma with hedgehog pathway inhibitor GDC-0449. N Engl J Med. 2009;361(12):1173-1178.

26. Yauch RL, Dijkgraaf GJ, Alicke B, et al. Smoothened mutation confers resistance to a Hedgehog pathway inhibitor in medulloblastoma. Science. 2009;326(5952):572-574.

27. Dijkgraaf GJ, Alicke B, Weinmann L, et al. Small molecule inhibition of GDC-0449 refractory smoothened mutants and downstream mechanisms of drug resistance. Cancer Res. 2011;71(2):435-444.

28. Metcalfe C, de Sauvage FJ. Hedgehog fights back: mechanisms of acquired resistance against smoothened antagonists. Cancer Res. 2011;71(15):5057-5061.
29. Buonamici S, Williams J, Morrissey M, et al. Interfering with resistance to smoothened antagonists by inhibition of the PI3K pathway in medulloblastoma. Sci Transl Med. 2010;2(51):51ra70.

30. Siu LL, Papadopoulos K, Alberts SR, et al. A first-in-human, phase I study of an oral hedgehog $(\mathrm{HH})$ pathway antagonist, BMS-833923(XL-139), in subjects with advanced or metastatic solid tumors. J Clin Oncol. 2010;28(15s):Abstr 2501 (oral presentation can be viewed at: http:// www.asco.org/ASCOv2/MultiMedia/Virtual+Meeting?\&vmview=vm session_presentations_view\&confID=74\&sessionID=3239).

31. Rodon Ahnert J, Baselga J, Tawbi H, et al. A phase I dose-escalation study of LDE225, a smoothened (Smo) antagonist, in patients with advanced solid tumors. J Clin Oncol. 2010;28(15s):Abstr 2500.

32. Stephenson J, Richards D, Wolpin B, et al. The safety of IPI-926, a novel hedgehog pathway inhibitor in combination with gemcitabine in patients with metastatic pancreatic cancer. J Clin Oncol. 2011;29(15s) Abstr 4114.

33. Jamieson C, Cortes JE, Oehler V, et al. Phase I dose-escalation study of $\mathrm{PF}-04449913$, an oral hedgehog $(\mathrm{Hh})$ inhibitor, in patients with select hematologic malignancies. Blood. 2011;118(21):Abstr 424

34. Skvara H, Kalthoff F, Meingassner JG, et al.Topical treatment of Basal cell carcinomas in nevoid Basal cell carcinoma syndrome with a smoothened inhibitor. J Invest Dermatol. 2011;131(8):1735-1744.

35. Uhmann A, Niemann H, Lammering B, et al. Antitumoral effects of calcitriol in basal cell carcinomas involve inhibition of hedgehog signaling and induction of vitamin D receptor signaling and differentiation. Mol Cancer Ther. 2011;10(11):2179-2188.

36. Hyman JM, Firestone AJ, Heine VM, et al. Small-molecule inhibitors reveal multiple strategies for Hedgehog pathway blockade. Proc Natl Acad Sci US A. 2009;106(33):14132-14137.

37. Lauth $M$, Bergström $A$, Shimokawa $T$, Toftgård R. Inhibition of GLI-mediated transcription and tumor cell growth by small-molecule antagonists. Proc Natl Acad Sci U S A. 2007;104(20):8455-8460.

38. Chenna V, Hu C, Pramanik D, et al. A polymeric nanoparticle encapsulated small-molecule inhibitor of hedgehog singaling (NanoHHI) bypasses secondary mutational resistance to smoothened antagnoists. Mol Cancer Ther. 2012;11(1):165-173.

39. Hosoya T, Arai MA, Koyano T, Kowithayakorn T, Ishibashi M. Naturally occurring small-molecule inhibitors of hedgehog/GLI-mediated transcription. Chem Bio Chem. May 5, 2008;9(7):1082-1092.

40. Hassounah NB, Bunch TA, McDermott KM. Molecular pathways: The role of primary cilia in cancer progression and therapeutics with a focus on hedgehog signaling. Clin Cancer Res. 2012;18(9):2429-2435.

41. ClinicalTrials.gov. Clinical trial search list at clinicaltrials. gov website. Available from: http://clinicaltrials.gov. Accessed May 19, 2012.

42. Pan Y, Bai CB, Joyner AL, Wang B, et al. Sonic hedgehog signaling regulates Gli2 transcriptional activity by suppressing its processing and degradation. Mol Cell Biol. 2006;26(9):3365-3377.

43. Sasaki H, Nishizaki Y, Hui C, et al. Regulation of Gli2 and Gli3 activities by an amino-terminal repression domain: implication of Gli2 and Gli3 as primary mediators of Shh signaling. Development. $1999 ; 126: 3915-3924$
Journal of Experimental Pharmacology

\section{Publish your work in this journal}

The Journal of Experimental Pharmacology is an international, peerreviewed, open access journal publishing original research, reports, reviews and commentaries on all areas of laboratory and experimental pharmacology. The manuscript management system is completely online and includes a very quick and fair peer-review system.

\section{Dovepress}

Submit your manuscript here: http://www.dovepress.com/journal-of-experimental-pharmacology-journal 